\title{
Ocular adnexal (orbital) solitary fibrous tumor: nuclear STAT6 expression and literature review
}

\author{
Aleksandra Petrovic • Aurélie Obéric • \\ Alexandre Moulin • Mehrad Hamedani
}

Received: 27 August 2014 / Revised: 26 January 2015 / Accepted: 18 February 2015 / Published online: 13 March 2015

(C) Springer-Verlag Berlin Heidelberg 2015

\begin{abstract}
Purpose To report the clinico-pathological features of solitary fibrous tumor occurring in the ocular adnexa $(\mathrm{OA})$ in a single center. To assess the presence of NAB2-STAT6 genes fusion in OA solitary fibrous tumor detected by nuclear overexpression of STAT6.

Methods Retrospective study including orbital and OA solitary fibrous tumors treated between 2006 and 2014 in our center. The clinical, radiological, and histopathological findings were evaluated. STAT6 expression was assessed by immunohistochemistry.

Results Five patients were identified and presented with a chronic OA mass. The tumors were radiologically well delimited, highly vascularized and without bone erosion. All the patients underwent complete surgical excision. Pathological examination confirmed solitary fibrous tumor in all cases. All tumors demonstrated a nuclear expression of STAT6. There were no recurrences, with a mean follow-up of 5 years after surgery.

Our review demonstrated that proptosis was the most common presentation occurring in $60 \%$ of the cases. In the ocular adnexa, adverse histological criteria were found in $19.7 \%$ of the tumors, and recurrences were observed in $48 \%$ of these cases. Thirty-six percent of patients presented at least one
\end{abstract}

Alexandre Moulin and Mehrad Hamedani contributed equally to this work.

A. Petrovic $\cdot$ A. Obéric $\cdot$ A. Moulin $\cdot$ M. Hamedani $(\bowtie)$ Department of Ophthalmology, University of Lausanne, Jules-Gonin Eye Hospital, 15 Avenue de France, 1004 Lausanne, Switzerland e-mail: mehrad.hamedani@fa2.ch

A. Obéric $\cdot$ M. Hamedani

Eye Plastic and Reconstructive Surgery, Lausanne, Switzerland

A. Moulin

Eye Pathology Laboratory, Lausanne, Switzerland local recurrence, and metastastic spread was found in $2.4 \%$ of the cases. Tumor-related death was described in two cases. Conclusion Ocular adnexal SFT are rare and usually present as a chronic orbital mass with proptosis. In the OA, solitary fibrous tumor demonstrates STAT6 nuclear expression, as documented in other locations. Recurrences are unusual and metastasis exceptional. Initial surgical resection should be complete in order to avoid recurrence.

Keywords Solitary fibrous tumor · Orbit · STAT6 · NAB2

\section{Introduction}

Solitary fibrous tumor (SFT) was probably initially reported in the pleura in 1760 by Lieutaud [1], but the first accurate pathological description was reported in 1931 by Klemperer and Rabin [2]. At that time, the tumor was named "localized mesothelioma" and was opposed to the diffuse pleural mesothelioma [3, 4]. Although more commonly arising in the pleura, SFT can occur in many sites, including meninges, oral cavity, pericardium, peritoneum, kidney, and liver [5-7]. In the ocular adnexa (OA), including orbit, eyelid, lacrimal gland, lacrimal sac, and conjunctiva, it has rarely been reported, with less than 130 cases documented to date in the English literature [8-85]. As most reported cases occurring in the OA are isolated case reports, the precise management of these tumors of intermediate malignancy level is not clearly defined. The behavior is often unpredictable, and does not always correlate with histological findings.

The recent identification of NAB2-STAT6 genes fusion using whole exome sequencing represents a breakthrough in the understanding of SFT pathogenesis [86, 87]. NAB2 (NGFI-A binding protein 2) is a transcriptional repressor of the transcription factor EGR1. STAT6 (signal transducer and 
activator of transcription 6) is a transcriptional activator involved in interleukin 4 signaling. NAB2 and STAT6 are both located closely to each other on the chromosomal band 12q13. Their fusion leads to the production of a chimeric protein that has been shown in vitro to induce cellular proliferation through the activation of early growth response genes (EGR1) $[86,87]$. As the inversion can be difficult to detect using by conventional in-situ hybridization, Doyle and al. demonstrated that nuclear expression of the carboxy terminal part of STAT6 was highly sensitive and specific of SFT, allowing the distinction between those tumors from histologic mimics [88]. In the normal bronchial epithelium, STAT6 predominantly localizes to the cytoplasm [89], but in meningeal SFT with NAB2-STAT6 fusion detected by sequencing or Duolink in-situ assay, a nuclear localization of STAT6 was demonstrated [90] .

We present here a clinico-pathological study including all the cases of OA SFT that occurred between 2006 and 2013 in our institution. We also assess the expression of STAT6, which has not been extensively evaluated in orbital solitary fibrous tumor.

\section{Material and methods}

\section{Clinical analysis}

We conducted a single-center, retrospective, non-comparative case review study of all patients who presented between 2006 and 2014 with histological diagnosis of SFT. Patient files were reviewed to retrieve clinical data including patient demographics (age, sex, race), past medical history, symptoms, clinical presentation, radiological findings, treatment modalities, and outcomes. All patients were operated by the same surgeon (MH). This study was approved by the Swiss Federal Department of Health (authorization no 035.0003-48) and is in accordance with the Declaration of Helsinki.

\section{Histopathologic analysis}

The tumors were formalin-fixed, macroscopically processed, and dehydrated through graded alcohol followed by paraffin inclusion. Sections of $5 \mu \mathrm{m}$ were cut, and hematoxylin-eosin and periodic acid-Schiff stains were performed.

Immunohistochemistry was performed on formalin-fixed paraffin-embedded (FFPE) tissue sections representative of the solitary fibrous tumor. After epitope retrieval at $\mathrm{pH} 6.0$ or $\mathrm{pH} 9.0$, endogenous peroxidase was blocked by $4 \%$ hydrogen peroxide for $10 \mathrm{~min}$. The sections were incubated with several anti-human antibodies (anti-CD34, mouse monoclonal, DAKO, 1:300; anti-BCL2, mouse monoclonal, DAKO, 1:100; anti-STAT6 against the carboxy terminal part, rabbit polyclonal, Santa Cruz, sc-621, 1:1000). A streptavidin/ biotin detection method with 3.3'-diaminobenzidine tetrachloride (DAB) was used for signal detection (DAKO Envision $^{\mathrm{TM}}+$ System/ HRP Dual Link). The percentage of immunoreactive cells was graded by two independent observers in the following manner: $0 \%-10 \%, 1+; 10-50 \%, 2+; 50-$ $100 \%, 3+$.

\section{Literature review strategy}

Systematic review of the literature was undergone using Pubmed, Web of Science using the key words "solitary fibrous tumor", "orbit", "eyelid", "conjunctiva”, "ocular adnexa", "lacrimal gland", "lacrimal sac", and "NAB2STAT6".

Statistical analysis

Statistical analysis was performed using JUMP 8.0 software.

\section{Results}

Clinical findings

There were four women and one male with a mean age of 36 years (26-68 years). Past medical history was unremarkable. The clinical and radiological findings are summarized in Table 1. The patients presented with a unilateral, indolent mass that was slowly progressing over months in four cases (patients 2-5), and in one case the patient (1) noticed a periocular mass 2 years ago with a recent and rapid increase in size during pregnancy (Fig. 1). Patient 4 complained of unilateral tearing (Fig. 2). In all patients, visual acuity was 1.0 (decimal scale), ocular motility was not limited and intraocular examination was unremarkable. There was no proptosis. In patient 4 , there was no obstruction of the lacrimal drainage system.

Four patients underwent preoperative MRI, and presented well-defined, non-infiltrative tumors with an isointense T1weighted signal. Within these tumors, hypointense flow voids could be observed. All the tumors demonstrated a strong contrast enhancement, which was homogenous in three cases and heterogenous in one case. On T2-weighted signal, the tumors showed a variable signal, isointense in two cases and slightly hyperintense in one case. One patient underwent CT scan, in which there was no bone erosion.

All patients had surgical resection through an anterior orbital access. Surgery allowed a complete resection in all the cases. Patient 1 underwent preoperative arterial embolization of the infra-orbital artery.

After surgery, all patients retained 1.0 visual acuity, full range of extra ocular movements, and symmetric exophthalmometric readings. Tearing disappeared after surgery for patient 4 . No postoperative complication was 
Table 1 Clinical and radiological presentation

\begin{tabular}{|c|c|c|c|c|c|}
\hline Patient & Age & Sex & Clinical presentation & $\begin{array}{l}\text { Symptoms } \\
\text { duration (months) }\end{array}$ & Radiological findings \\
\hline 1 & 28 & $\mathrm{~F}$ & Left inferior orbital mass & 24 & $\begin{array}{l}\text { T1: isointense signal } \\
\text { Proeminent hypointense vessels. No bone erosion. } \\
\text { Contrast enhancement : strong and homogenous } \\
\text { T2: isointense signal }\end{array}$ \\
\hline 2 & 68 & $\mathrm{~F}$ & Right superior orbital mass & 24 & $\begin{array}{l}\text { Isodense, well defined mass without bone erosion. } \\
\text { Contrast enhancement: } \\
\text { homogenous. }\end{array}$ \\
\hline 3 & 26 & $\mathrm{~F}$ & $\begin{array}{l}\text { Left supero-temporal orbital mass } \\
\text { with subconjonctival procidence } \\
\text { in the lateral canthus }\end{array}$ & 12 & $\begin{array}{l}\text { T1: isointense signal with hypointense vascular } \\
\text { channels. No bone erosion, no infiltration } \\
\text { of adjacent fat } \\
\text { Contrast enhancement: } \\
\text { strong, heterogenous } \\
\text { T2 : heterogenous, isointense and hypointense signal }\end{array}$ \\
\hline 4 & 29 & $\mathrm{~F}$ & $\begin{array}{l}\text { Right tearing and right medial } \\
\text { orbital mass. }\end{array}$ & 1 & $\begin{array}{l}\text { T1: isointense signal with focal hypointense areas } \\
\text { No bone erosion, no infiltration of adjacent tissue } \\
\text { Contrast enhancement: strong, homogenous. } \\
\text { T2: slightly hyperintense, homogenous signal. }\end{array}$ \\
\hline 5 & 29 & M & $\begin{array}{l}\text { Right medial canthal mass appeared } \\
\text { after trauma. }\end{array}$ & 20 & $\begin{array}{l}\text { T1: isointense signal. No bone erosion, no infiltration } \\
\text { of adjacent tissue. } \\
\text { Contrast enhancement: strong and homogenous } \\
\text { T2: heterogenous signal with discret hyperintense } \\
\text { signal }\end{array}$ \\
\hline
\end{tabular}

reported. Local recurrence did not happen in any of our patients, with a mean follow-up of 5 years (1-7 years).

Histopathological findings

Microscopic examination showed in all cases a proliferation of spindle cells with minimal to mild pleomorphism, organized in sheets or in whorls. The histopathological findings are summarized in Table 2. Most of the tumors were densely cellular; less cellular areas with a loose, focally myxoid stroma could be identified in two cases. The cells were separated by collagen bundles that were locally thickened (Fig. 3). Capsular infiltration was noted in one case. No cases harbored more than 2 mitoses/10
Fig. 1 Case 1, patient with left inferior orbital solitary fibrous tumor. a Clinical photography during initial presentation showing a firm bluish mass. $\mathbf{b}$ Profile photography. c Coronal T2 MRI image showing a welldefined, iso-intense masse, with area of mild hyperintense intensity. d Sagittal T1 MRI image depicting a marked enhancement after Gadolinium injection
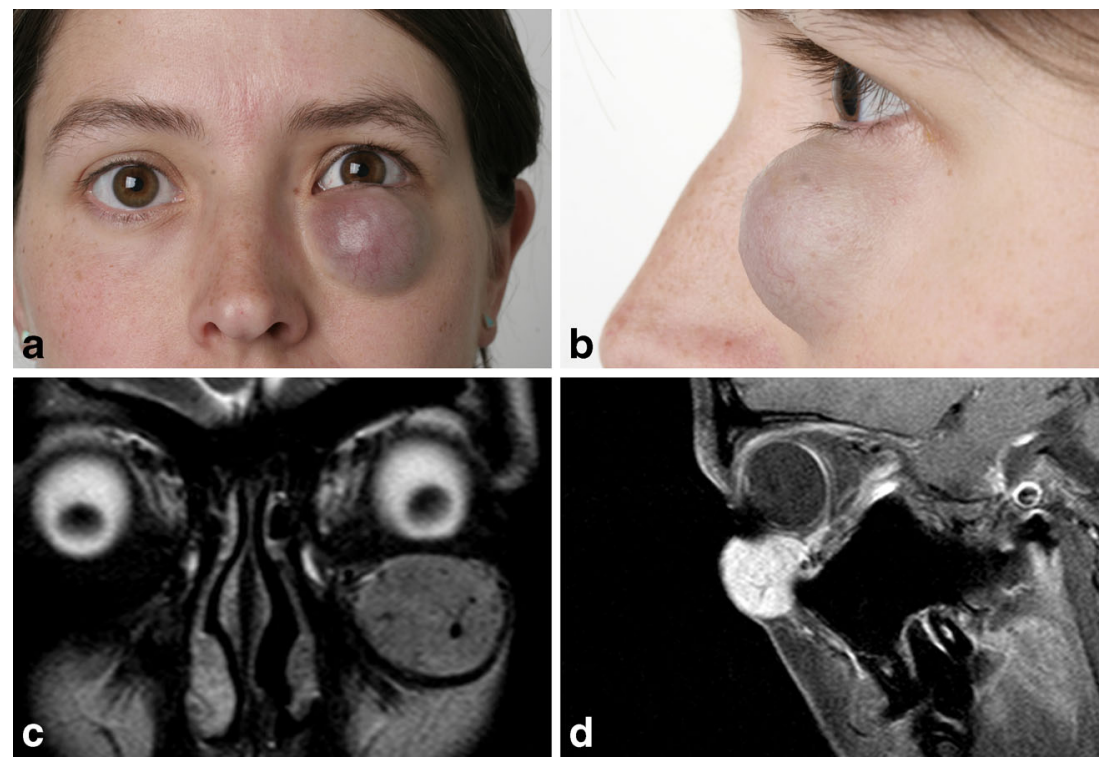
Fig. 2 Case 4, patient with right orbital solitary fibrous tumor. a Clinical photography of a patient with right internal orbital mass complaining of tearing. b Axial T1 MRI image showing an intense enhancement after gadolinium injection
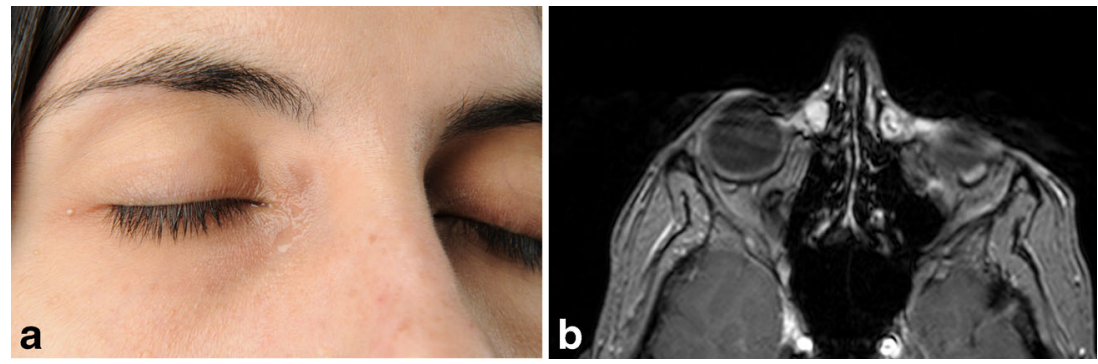

HPF, and no necrosis could be identified. In three cases, branching, staghorn vessels could be observed. Occasional giant cells were found in three cases. In one case, embolic material surrounded by macrophages and neutrophils could be found within the vessels.

On immunohistochemistry, all the tumors expressed diffusely CD34 (+++) and STAT6 (+++) (Fig. 4). STAT6 expression was strongly expressed in the nuclei. BCL2 was found diffusely expressed in three cases $(+++)$ and in a smaller proportion of cells in one case $(++)$.

\section{Discussion}

The occurrence of solitary fibrous tumor in the OA is rare, with 130 documented cases to date, including the cases described in our study (summarized in Table 3). Women appear to be slightly more commonly involved $(53 \% ; 65 / 122)$ than men $(47 \%, 57 / 122)$. Orbital SFT can occur in all age groups, ranging from 5 years old [68] to 94 years old [60], but they peak in the fourth decade, with a mean age of $41.6( \pm 1.79$ SEM) years old.

Our retrospective analysis demonstrated that orbit is the most frequent site affected, with proptosis the most common presentation, occurring in $60 \%$ of the patients (74/124). Patients noticed a mass in $40 \%$ of the cases (50/126). Ptosis and tearing, as presented in our study, were rather uncommon findings, occurring in respectively $3.2 \%(4 / 126)$ and $1.6 \%$ of the cases (2/126). Two patients presented with palpebral mass $[82,84]$ and one with tumor of the conjunctiva [83]. Most of the tumors were extraconal $(92.9 \%, 105 / 113)$. In reviewing 97 cases with available information, SFT manifested a slow, indolent growth with mean symptom duration of 3.2 years ( \pm 6.6 months SEM). In the previous reported cases, visual acuity was always conserved, except in cases with optic nerve function impairment due to mechanical distension $[52,73]$ or tumor development on optic nerve sheath $[71,78]$.

In our study, one of our patients presented a sudden increase in tumor size during her pregnancy, as already documented in the literature [43]. The identification of estrogen as well as progesterone receptors in SFT [91] might explain the abrupt change in tumor volume observed in these patients during their pregnancy.

On CT and MR images, the majority of SFTs appeared ovoid in configuration and had well-defined margins [92-94]. On MR imaging, all SFT showed isointense signal intensity on T1-weighted images compared to cerebral grey matter [92-94]. On T2-weighted images, SFT appeared heterogeneous and have been described as isointense [92], hypointense [92, 93], or mixed iso-hyperintense [94]. On both CT and MR imaging, SFT showed marked enhancement after contrast injection [92-94]. The time intensity curve often showed an early washout pattern, characteristic of SFT on MR imaging $[92,93]$. SFT can also present as a cystic lesion $[46,72,73,77]$ or can demonstrate intra-tumoral calcification $[61,72]$.

The principal radiological differential diagnosis of SFT needs to be established with cavernous hemangioma. Cavernous hemangioma appears isointense on T1-weighted images, as with SFT, but unlike SFT is markedly hyperintense
Table 2 histopathological analysis

\begin{tabular}{llllll}
\hline Patients & 1 & 2 & 3 & 4 & 5 \\
\hline Cellularity & +++ & ++ & ++ & +++ & ++ \\
Mitoses/10 HPF & 1 & 2 & 0 & 1 & 0 \\
Capsular infiltration & Yes & No & No & No & No \\
Necrosis & No & No & No & No & No \\
Cellular pleomorphism & Mild & Mild to moderate & Mild & Mild & Mild \\
Giant cells & Occasional & Occasional & Absent & Absent & Occasional \\
BCL2 & +++ & +++ & ++ & +++ & +++ \\
CD34 & +++ & +++ & +++ & +++ & +++ \\
STAT6 & +++ & +++ & +++ & +++ & +++ \\
\hline
\end{tabular}


Fig. 3 a Hematoxylin \& eosin, $63 \times$. SFT are populated by sheets of spindle cells containing localized, dense collagenous areas. b Hematoxylin \& eosin, 126×. The stroma harbours branching, staghorn-shaped vessels. The cellular pleomorphism is mild. c CD34 immunohistochemistry, 126×. The tumor cells diffusely express CD34. d BLC2 immunohistochemistry, $126 \times$. There is also a diffuse and strong expression of BCL2
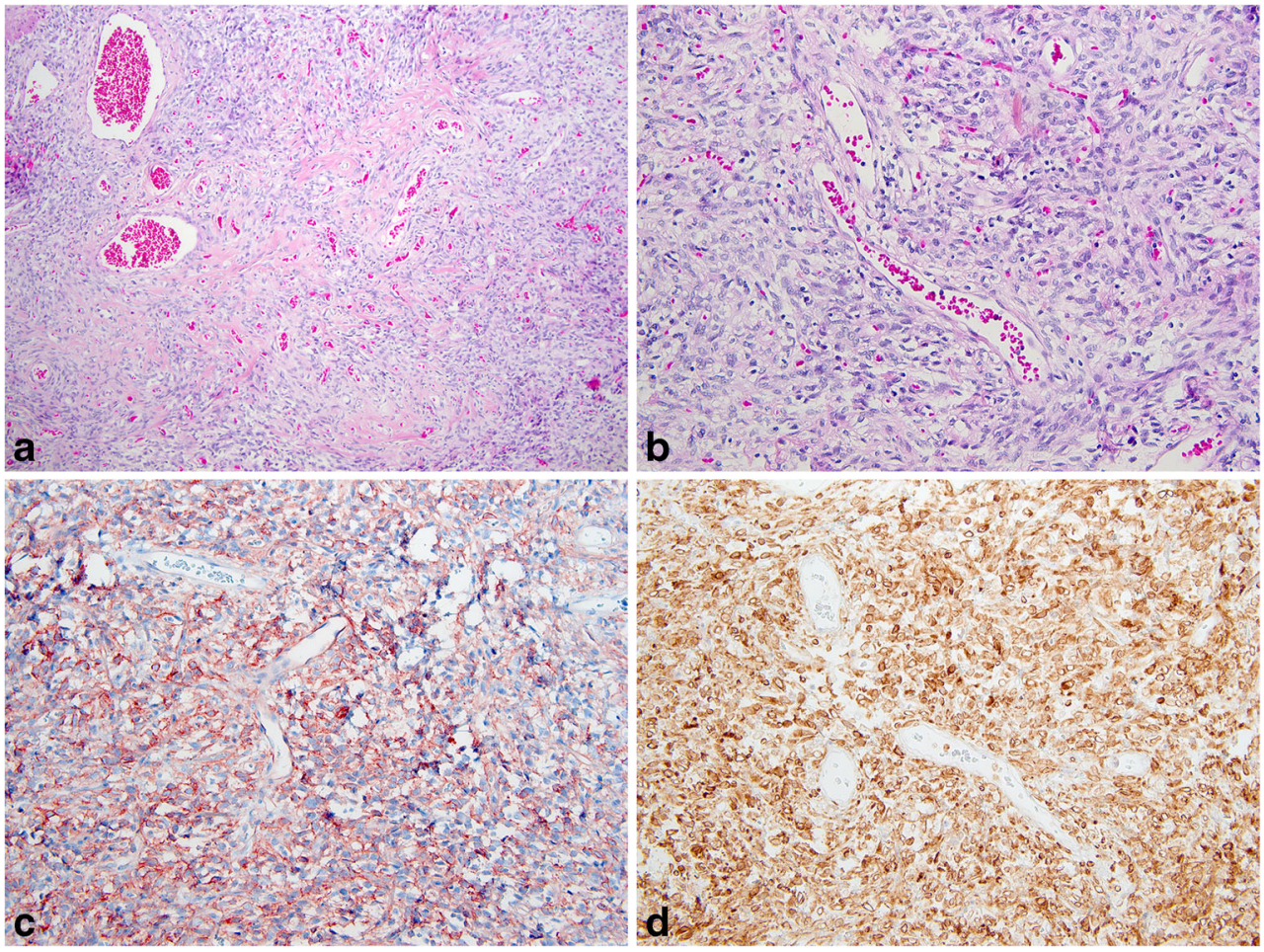

on T2-weighted images compared to extraocular muscle [95]. SFT often shows a feeder artery forming a pedicle which enters the tumor and branches radially, a finding that is uncommon in cavernous haemangioma [96].

The microscopic diagnosis of SFT relies on the identification of sheets of spindle cells admixed with branching, staghorn vessels with an alternation of cellular areas and less cellular areas. The stroma contains thickened collagen bundles. Adverse prognosis criteria previously described include: size superior to $5 \mathrm{~cm}$, hypercellularity, elevated mitotic index ( $>4$ mitosis/10 HPF), cellular pleomorphism, infiltrated surgical margin, and necrosis [97]. In
Fig. 4 a-d. STAT6

immunohistochemistry, 126×. All the tumors demonstrated a diffuse and strong nuclear expression of the carboxy terminal part of STAT6
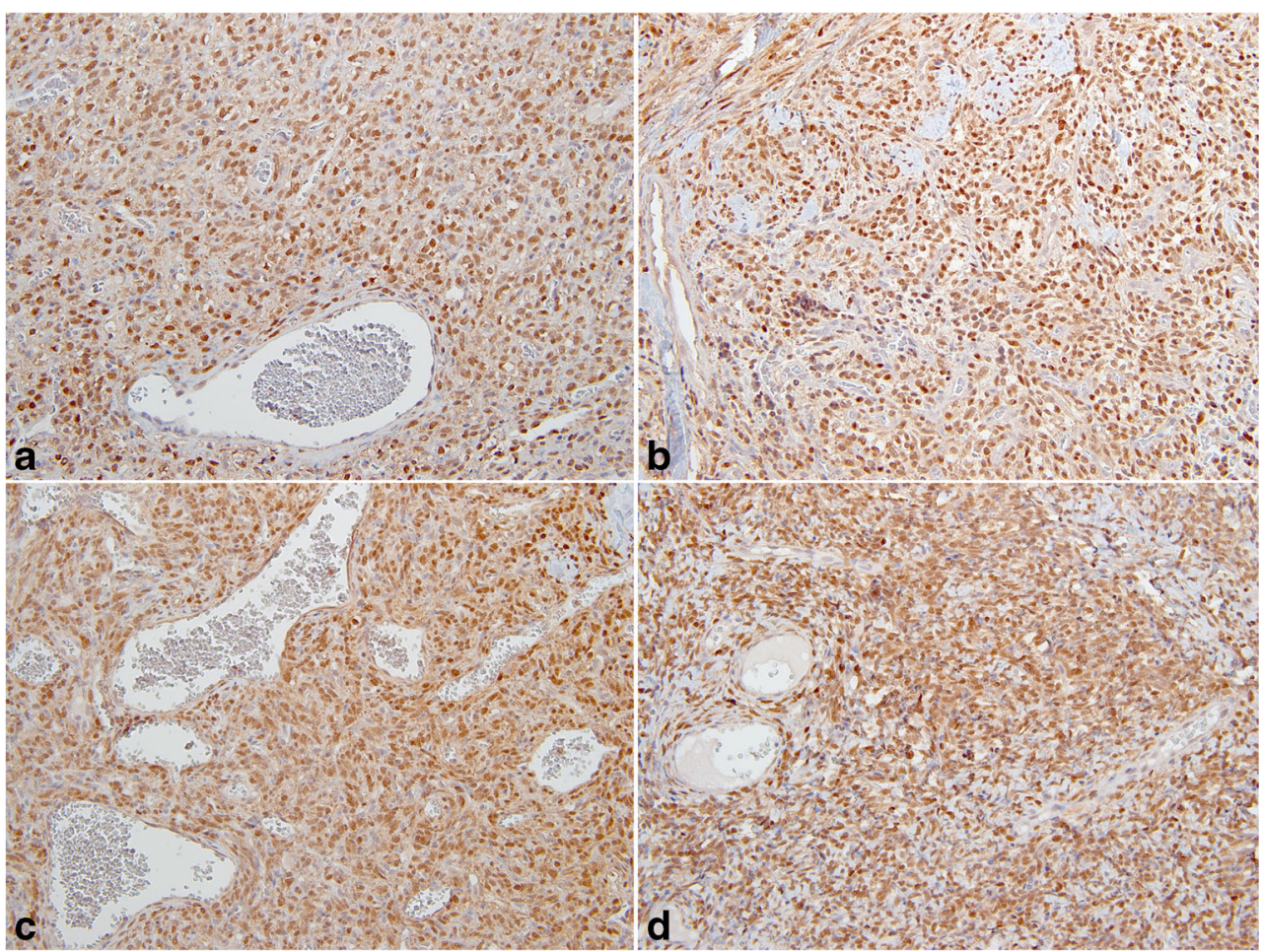
Table 3 Review of the literature

\begin{tabular}{|c|c|}
\hline Mean age at presentation & $41.6 \pm 1.8(\mathrm{SEM})$ \\
\hline Female & $53.3 \%(65 / 122)$ \\
\hline \multicolumn{2}{|l|}{ Clinical presentation } \\
\hline - proptosis & $\begin{array}{l}59.2 \%(74 / 125)[8,15,16,18-20,22,24-31,33-38,40-46,48,49,52,54,55 \text {, } \\
\quad 57-64,66,68,71-76,78,79]\end{array}$ \\
\hline - palpable mass & $\begin{array}{l}39.7 \%(50 / 126)[8,17,20,23,34,35,38,41,46-48,50,53,56,59,63,65-67, \\
\quad 69-71,73,77,80,81]\end{array}$ \\
\hline - ptosis & $3.2 \%(4 / 126)[40,48,59]$ \\
\hline - tearing & $1.6 \%(2 / 126)[8,64]$ \\
\hline - other & $3.2 \%(4 / 126)[24,32,48,73]$ \\
\hline \multicolumn{2}{|l|}{ Localisation } \\
\hline - intraconal & $7.3 \%$ \\
\hline - extraconal & $92.9 \%(105 / 113)$ \\
\hline \multicolumn{2}{|l|}{-orbital } \\
\hline -orbital lacrymal gland & $5.5 \%(7 / 126)[34,40,41,69,85]$ \\
\hline -eyelid & $1.6 \%(2 / 126)[82,84]$ \\
\hline -conjunctiva & [83] \\
\hline -lacrymal sac & {$[50]$} \\
\hline Symptoms duration (years) & $3.2( \pm 6.6$ months $)$ \\
\hline Adverse histopathological factors & $17.2 \%(17 / 99)$ \\
\hline $\begin{array}{l}\text { (at least one adverse prognostic factor: size }>5 \mathrm{~cm} \text {, } \\
>4 \text { mitosis } / 10 \mathrm{HF} \text {, necrosis, pleomophism) }\end{array}$ & {$[16,17,20,33,36-38,49,62,64,66,67,71,73,75]$} \\
\hline \multicolumn{2}{|l|}{ Treatment } \\
\hline -surgery & $100 \%(130 / 130)$ \\
\hline -adjunctive radiotherapy & $8.2 \%(10 / 121)[17,30,41,56,66,68,74,75]$ \\
\hline \multicolumn{2}{|l|}{ Immunochemistry } \\
\hline$-\mathrm{CD} 34+$ & $99.2 \%(123 / 124)[8-27,29-44,46-52,54-60,62-81]$ \\
\hline$-\mathrm{CD} 99+$ & $92 \%(46 / 51)[30,40,42,46-48,56-58,61,63-66,68,69,71,72,78-80]$ \\
\hline$-\mathrm{Bc} 12+$ & $79.5 \%(35 / 45)[8,30,37,46-48,57,58,61,63,65,66,68,71,74,75,77-80]$ \\
\hline Recurrence & $\begin{array}{l}36.5 \%(31 / 85)[8,17,29,30,36,38,41,45,49-51,56,57,59,64,66,68,71 \\
\quad 73,75]\end{array}$ \\
\hline Time to first recurrence (month) & $16.06 \pm 3.87$ (SEM) \\
\hline Metastasis & $2.4 \%(2 / 87)[56,64]$ \\
\hline Death due to SFT & $2.5 \%(2 / 81)[38,64]$ \\
\hline Follow-up (mean, months) & $37.3 \pm 6.34(\mathrm{SEM})$ \\
\hline
\end{tabular}

the orbit, our review demonstrated that at least one adverse histological criteria was found in $19.7 \%$ of the tumors (23/86), and recurrences were observed in $48 \%$ of these cases $(11 / 23)$. Four patients presented a transformation into fibrosarcoma after multiple recurrences [17, 30, 38, 66]. Previous study reported that adverse prognostic factors were associated with an aggressive clinical behavior, but were not by themselves predictive of such a behavior [5]. The immunohistohemical profile of SFT includes expression of CD34, CD99, and variable expression of BLC2. Strong and homogenous presence of CD34 within SFT was first described in 1994 [19]. In the previous reported cases, tumors showed intense and diffuse CD34 and CD99 reaction in more than $90 \%$ of the cases (Table 3).
The recent identification of NAB2-STAT6 inversion on chromosome 12 not only constitutes an important step in the mechanistic understanding of the molecular pathogenesis of SFT, but also enhances the possibilities of its diagnosis. Doyle and al. analyzed the presence of the carboxy terminal STAT6 portion in cell nucleus and confirmed its presence in $98 \%$ of cases [88]. Other mesenchymal tumors tested in the same study did not show STAT6 reactivity. In our patients, all tumors were expressing STAT6 in the nuclei, strongly suggesting the presence of NAB2-STAT6 inversion. A recent series, yet unpublished, also confirmed STAT6 expression in 12 orbital SFT [98].

All OA SFT reported in the literature were treated with surgical resection, except for two cases where 
exenteration was necessary due to cranial bone invasion $[38,75]$. In both cases, tumor recurred months after surgery in the orbit. Nine patients with orbital SFT were treated with complementary radiotherapy $[17,30,41$, $56,66,68,74,75]$, with doses ranging from 40 Gy [56] to 50.4 Gy [66]. In six incompletely resected or recurrent SFT, complementary radiotherapy did not prevent further recurrences [56, 68].

According to Houdt et al. [99], orbital and extra-orbital SFT have a recurrence rate of $29 \%$ at 5 years, a general metastatic rate of $34 \%$, and a mortality rate of $16 \%$ (Table 3). In our review, we identified 31 patients $(31 / 85)$ with at least one local recurrence ( $36 \%$, mean follow-up of 37 months). Two patients developed metastasis $(2.4 \%)$ $[56,64]$, and in two patients death was attributed to SFT. The rate of local recurrence appears to be similar between orbital and non-orbital SFT, but metastasis rate is much higher in non-orbital SFT, possibly due the earlier clinical detection of orbital SFT. In the two patients with orbital SFT and metastatic behavior, the tumor had initially not been completely resected and recurred several times. In previously published cases, metastasis only occurred in cases with local recurrence and loss of local tumor control. Based upon these findings, it appears that one evaluation seems to be particularly relevant for incompletely resected tumor. The role of systemic follow up of incompletely resected tumors seems to be less important, but further studies are required to address this issue.

Local recurrences developed as soon as 3 months after surgery to 20 years (mean of 16 months). In most cases of local recurrence, SFT was initially described as incompletely excised. However, recurrences have been described even with complete surgery, suggesting that other unknown factors have to be incriminated in the malignant and invasive transformation of those tumors [75].

Considering that SFT arising in the OA seem to be associated with a lower metastatic spread than systemic SFT, we sought to evaluate if OA SFT and systemic SFT share common pathogenic mechanisms. In other tumors such as extranodal marginal zone lymphoma, different translocations have been demonstrated in different location $[100,101]$.

This article aims to present our experience with SFT and a large review of the literature, as well as an update of the new molecular aspects of this condition. We demonstrate that SFT can have different clinical presentation, proptosis being the more common, with slow and chronic growth without local inflammation. The identification of NAB2-STAT6 inversion specific of SFT can be detected by immunohistochemistry in orbital SFT. Complete surgical excision seems to reduce the local recurrence rate. The fact that recurrences can develop as long as 14 years after the surgery underlines the need for a long-term local follow-up.

\section{References}

1. Lieutaud J (1767) Historia anatomico-medica.Parisiis, apud Vincent

2. Klemperer P, Rabin CB (1931) Primary neoplasms of the pleura: a report of five cases. Arch Pathol 11:385-412

3. Stout AP, Murray MR (1942) Hemangiopericytoma: a vascular tumor featuring Zimmermann's pericytes. Ann Surg 116:26-33

4. Luse SA, Spjut HJ (1964) An electron microscopic study of a solitary pleural mesothelioma. Cancer 17:1546-1554

5. Vallat-Decouvelare AV, Dry SM, Fletcher CD (1998) Atypical and malignant solitary fibrous tumors in extrathoracic locations: evidence of their comparability to intra-thoracic tumors. Am J Surg Pathol 22:1501-1511

6. Vaswani K, Guttikonda S, Vitellas KM (2000) Case 1. Localized fibrous tumor of the liver. AJR Am J Roentgenol 175(3):872, 875876

7. Safneck JR, Alguacil-García A, Dort JC, Phillips SM (1993) Solitary fibrous tumour: report of two new locations in the upper respiratory tract. J Laryngol Otol 107:252-256

8. Bernardini FP, de Conciliis S, Schneider S, Kersten RC, Kulwin DR (2003) Solitary fibrous tumor of the orbit: is it rare? Report of a case series and review of the literature. Ophthalmology 110:1442-1448

9. Giuffrè I, Faiola A, Bonanno E, Liccardo G (2001) Solitary fibrous tumor of the orbit. Case report and review of the literature. Surg Neurol 56:242-246

10. Holbach LM, Colombo F, Schlötzer-Schrehardt U, Kirchner T (2002) Solitary fibrous tumor of the orbit presenting 20 years after Hodgkin's disease. Orbit 21:49-54

11. Luo SH, Kao SC, Pan CS (2003) Solitary fibrous tumor of the orbit. J Formos Med Assoc 102:726-728

12. Hsu SS, Lai PH, Wang JS, Yip CM (2004) Solitary fibrous tumor of the orbit. J Chin Med Assoc 67:483-486

13. Galiè M, Tieghi R, Cavazzini L, Clauser L (2005) Solitary fibrous tumor of the orbit: a case report. Int J Oral Maxillofac Surg 34:331333

14. Meyer D, Riley F (2000) Solitary fibrous tumor of the orbit: a clinicopathologic entity that warrants both a heightened awareness and an atraumatic surgical removal technique. Orbit 25:45-50

15. Warraich I, Dunn DM, Oliver JW (2006) Solitary fibrous tumor of the orbit with epithelioid features. Arch Pathol Lab Med 130:1039 1041

16. Mascarenhas L, Lopes M, Duarte AM, Romão H, Honavar M, Resende M, Rocha Vaz A (2006) Histologically malignant solitary fibrous tumor of the orbit. Neurochirurgie 52:415-418

17. Manousaridis K, Stropahl G, Guthoff RF (2001) Recurrent malignant solitary fibrous tumor of the orbit. Ophthalmologe 108:260 264. doi:10.1007/s00347-010-2277-6

18. Ruska KM, Westra WH (1996) Pathologic quiz case 1. Solitary fibrous tumor (SFT) of the orbit. Arch Otolaryngol Head Neck Surg 122(1130):1132

19. Westra WH, Gerald WL, Rosai J (1994) Solitary fibrous tumor. Consistent CD34 immunoreactivity and occurrence in the orbit. Am J Surg Pathol 18:992-998

20. Fenton S, Moriarty P, Kennedy S (2001) Solitary fibrous tumour of the orbit. Eye (Lond) 15:124-126

21. Romer M, Bode B, Schuknecht B, Schmid S, Holzmann D (2005) Solitary fibrous tumor of the orbit: two cases and a review of the literature. Eur Arch Otorhinolaryngol 262:81-88

22. Ramdial PK, Nadvi S (1996) An unusual cause of proptosis: orbital solitary fibrous tumor: case report. Neurosurgery 38:1040-1043

23. McElvanney AM, Noble JL, O'Donovan DG, Bonshek RE, Banerjee SS (1996) Solitary fibrous tumour: an atypical presentation within the orbit. Eye (Lond) 10:396-399 
24. Lanuza A, Lazaro R, Salvador M, Solanes C, Ramos F, Sorli E (1998) Solitary fibrous tumour of the orbit. Report of a new case. Int Ophthalmol 22:265-268

25. Fukunaga M, Ushigome S, Nomura K, Ishikawa E (1995) Solitary fibrous tumor of the nasal cavity and orbit. Pathol Int 45:952-957

26. de Saint Aubain Somerhausen N, Rubin BP, Fletcher CD (1999) Myxoid solitary fibrous tumor: a study of seven cases with emphasis on differential diagnosis. Mod Pathol 12:463-471

27. DeBacker CM, Bodker F, Putterman AM, Beckmann E (1996) Solitary fibrous tumor of the orbit. Am J Ophthalmol 121:447-449

28. Dorfman DM, To K, Dickersin GR, Rosenberg AE, Pilch BZ (1994) Solitary fibrous tumor of the orbit. Am J Surg Pathol 18:281-287

29. Alexandrakis G, Johnson TE (2000) Recurrent orbital solitary fibrous tumor in a 14-year-old girl. Am J Ophthalmol 130:373-376

30. Wang X, Qian J, Bi Y, Ping B, Zhang R (2013) Malignant transformation of orbital solitary fibrous tumor. Int Ophthalmol 33:299 303. doi:10.1007/s10792-012-9637-y

31. Tsukamoto Y, Watanabe T, Nishimoto S, Kakibuchi M, Yamada Y, Kohashi K, Oda Y, Hirota S (2014) STAT6-positive intraorbital papillary tumor : a rare variant of solitary fibrous tumor? Pathol Res Pract 210:450-533. doi:10.1016/j.prp.2014.03.001

32. Dériot JB, Ledoux-Pilon A, Pilon F, Ravel A, Déchelotte P, Rigal D, Chiambaretta F (2005) Tumeur fibreuse solitaire de l'orbite : une cause inhabituelle d'exophtalmie unilatérale. A propos d'un cas avec revue de la littérature. J Fr Ophtalmol 28:999-1005

33. Ahn JY, Shim JY, Yang WI, Kim TS (2001) Meningeal solitary fibrous tumor as an unusual cause of exophthalmos: case report and review of the literature. Neurosurgery 48:1362-1366

34. Kim HY, Lee SY, Kang SJ, Kim HJ (1999) Solitary fibrous tumor of the orbit: a poorly-recognized orbital lesion. Acta Ophthalmol Scand 77:704-708

35. Harmouch A, Chefchaouni MC, Maher M, Sefiani S (2011) Tumeur fibreuse solitaire de l'orbite : à propos de deux cas avec revue de la littérature. J Fr Ophtalmol 34:133-137. doi:10.1016/j.jfo.2010.11.006

36. Hayashi S, Kurihara H, Hirato J, Sasaki T (2001) Solitary fibrous tumor of the orbit with extraorbital extension: case report. Neurosurgery 49:1241-1245

37. O'Donovan DA, Bilbao JM, Fazl M, Antonyshyn OM (2002) Solitary fibrous tumor of the orbit. J Craniofac Surg 13:641-644

38. Carrera M, Prat J, Quintana M (2001) Malignant solitary fibrous tumour of the orbit: report of a case with 8 years follow-up. Eye (Lond) 15:102-104

39. Kordic H, Bode-Lesniewska B, Pangalu A, Chaloupka K (2012) Solitary fibrous tumour of the orbit: clinical, radiological, histological findings and differential diagnosis of an uncommon tumour. Klin Monatsbl Augenheilkd 229:382-386. doi:10.1055/s-00311299219

40. Scott IU, Tanenbaum M, Rubin D, Lores E (1996) Solitary fibrous tumor of the lacrimal gland fossa. Ophthalmology 103:1613-1618

41. Polito E, Tosi GM, Toti P, Schürfeld K, Caporossi A (2002) Orbital solitary fibrous tumor with aggressive behavior. Three cases and review of the literature. Graefes Arch Clin Exp Ophthalmol 240: $570-574$

42. Leoncini G, Maio V, Puccioni M, Franchi A, De Giorgi V, Ucci F, Santucci M, Massi D (2008) Orbital solitary fibrous tumor: a case report and review of the literature. Pathol Oncol Res 14:213-217. doi:10.1007/s12253-008-9055-7

43. Das JK, Sharma AS, Deka AC, Das D (2009) Solitary fibrous tumor of the orbit presenting in pregnancy. Indian J Ophthalmol 57:238240. doi:10.4103/0301-4738.49405

44. Lucci LM, Anderson RL, Harrie RP, Mamalis N, Coffin C, Crandall DC (2001) Solitary fibrous tumor of the orbit in a child. Ophthal Plast Reconstr Surg 17:369-373

45. Young TK, Hardy TG (2011) Solitary fibrous tumor of the orbit with intracranial involvement. Ophthal Plast Reconstr Surg 27: e74-e76. doi:10.1097/IOP.0b013e3181ed3590
46. Bandyopadhyay R, Ghosh AK, Roy R, Mondol A, Mukhopadhyay S, Mukhopadhyay S (2011) Solitary fibrous tumour of the orbit: an unusual presentation. J Indian Med Assoc 109:676-677

47. Ribeiro SF, Chahud F, Cruz AA (2012) Orbital hemangiopericytoma/ solitary fibrous tumor in childhood. Ophthal Plast Reconstr Surg 28: e58-e60. doi:10.1097/IOP.0b013e3182232493

48. Gigantelli JW, Kincaid MC, Soparkar CN, Lee AG, Carter SR, Yeatts RP, Holck DE, Hartstein ME, Kennerdell JS (2001) Orbital solitary fibrous tumor: radiographic and histopathologic correlations. Ophthal Plast Reconstr Surg 1:207-214

49. Ing EB, Kennerdell JS, Olson PR, Ogino S, Rothfus WE (1998) Solitary fibrous tumor of the orbit. Ophthal Plast Reconstr Surg 14: 57-61

50. Woo KI, Suh YL, Kim YD (1999) Solitary fibrous tumor of the lacrimal sac. Ophthal Plast Reconstr Surg 15:450-453

51. Zoumalan CI, Egbert PR, Warwar RE (2008) Orbital giant cell angiofibroma recurring as a solitary fibrous tumor. Ophthal Plast Reconstr Surg 24:325-327. doi:10.1097/IOP. 0b013e31817dd6f5

52. Miller NR, Agrawal N, Sciubba JJ, Lane AP (2008) Image-guided transnasal endoscopic resection of an orbital solitary fibrous tumor. Ophthal Plast Reconstr Surg 24:65-67. doi:10.1097/IOP. 0b013e31815faa9d

53. Savino G, Aliberti S, Colucci D, Perrotta V, Balestrazzi E (2009) Atypical presentation of a case of solitary fibrous tumor of the orbit. Orbit 28:176-178

54. Adeleye AO, Ogun OA, Ogun GO (2010) Orbital solitary fibrous tumor. Another rare case from Africa. Int Ophthalmol 30:315-318. doi:10.1007/s10792-009-9320-0

55. Ha JK, Park BJ, Kim YH, Lim YJ (2009) Orbital solitary fibrous tumor: a case report and diagnostic clues. J Korean Neurosurg Soc 46:77-80. doi:10.3340/jkns.2009.46.1.77

56. Parrozzani R, Fusetti S, Montesco C, Favero V, Midena E (2013) Biphasic solitary fibrous tumor of the orbit with distant metastases. Int Ophthalmol 33:701-705. doi:10.1007/s10792012-9706-2

57. Demirci H, Shields CL, Eagle RC Jr, Shields JA (2009) Giant cell angiofibroma, a variant of solitary fibrous tumor, of the orbit in a 16year-old girl. Ophthal Plast Reconstr Surg 25:402-404. doi:10. 1097/IOP.0b013e3181b39a15

58. Pitchamuthu H, Gonzalez P, Kyle P, Roberts F (2009) Fat-forming variant of solitary fibrous tumour of the orbit: the entity previously known as lipomatous haemangiopericytoma. Eye (Lond) 23:14791481. doi: $10.1038 /$ eye. 2008.215

59. Tam ES, Chen EC, Nijhawan N, Harvey JT, Howarth D, Oestreicher JH (2008) Solitary fibrous tumor of the orbit: a case series. Orbit 27: 426-431. doi:10.1080/01676830802344508

60. Krause E, Gürkov R, Klauss V (2009) Solitary fibrous tumor in the orbit. Case report and review of the literature. HNO 57:169-172. doi:10.1007/s00106-008-1715-0

61. Girnita L, Sahlin S, Orrego A, Seregard S (2009) Malignant solitary fibrous tumour of the orbit. Acta Ophthalmol 87:464-467. doi:10. 1111/j.1755-3768.2008.01290

62. Wallace KM, Alaraj A, Aakalu VK, Aletich V, Setabutr P (2013) Endovascular preoperative embolization of orbital hemangiopericytoma with n-butyl cyanoacrylate glue. Ophthal Plast Reconstr Surg 2013 Dec 5. [Epub ahead of print]

63. Le CP, Jones S, Valenzuela AA (2014) Orbital solitary fibrous tumor: a case series with review of the literature. Orbit 33:145-151. doi: $10.3109 / 01676830.2013 .853806$

64. Chen H, Xiao CW, Wang T, Wu JS, Jiang CC, Qian J, Wei CH, Wang XQ (2012) Orbital solitary fibrous tumor: a clinicopathologic study of ten cases with long-term follow-up. Acta Neurochir (Wien) 154:249-255. doi:10.1007/s00701-011-1254-4, discussion 255 
65. Mulay K, Honavar SG (2013) Orbital solitary fibrous tumor with multinucleate giant cells: case report of an unusual finding in an uncommon tumor. Indian J Pathol Microbiol 56:282-284. doi:10. 4103/0377-4929.120399

66. Blandamura S, Alaggio R, Bettini G, Guzzardo V, Valentini E, Bedogni A (2014) Four cases of solitary fibrous tumour of the eye and orbit: one with sarcomatous transformation after radiotherapy and one in a 5-year-old child's eyelid. J Clin Pathol 67:263-267. doi:10.1136/jclinpath-2013-201820

67. Rose AM, Kabiru J, Rose GE (2013) A rare case of orbital haemangiopericytoma arising in childhood. Orbit 32:384-386. doi: $10.3109 / 01676830.2013 .815226$

68. Griepentrog GJ, Harris GJ, Zambrano EV (2013) Multiply recurrent solitary fibrous tumor of the orbit without malignant degeneration: a 45-year clinicopathologic case study. JAMA Ophthalmol 131:265267. doi:10.1001/2013.jamaophthalmol.69

69. da Son H, Yoo SH, Sa HS, Cho KJ (2013) A solitary fibrous tumor with giant cells in the lacrimal gland: a case study. J Korean Pathol 47:158-162. doi:10.4132/KoreanJPathol.2013.47.2.158

70. Schellini SA, Hoyama E, Marques ME, Abreu ES, Yamashita S (2003) Orbital solitary fibrous tumor: report of two cases and literature review. Jpn J Ophthalmol 47:415-418

71. Graue GF, Schubert HD, Kazim M (2013) Correlation between clinical features, imaging and pathologic findings in recurrent solitary fibrous tumor of the orbit. Orbit 32:375-380. doi:10.3109/ 01676830.2013 .815222

72. Polomsky M, Sines DT, Dutton JJ (2013) Solitary fibrous tumor of the orbit with multiple cavities. Ophthal Plast Reconstr Surg 29: e117-e119. doi:10.1097/IOP.0b013e318279fdd6

73. Krishnakumar S, Subramanian N, Mohan ER, Mahesh L, Biswas J, Rao NA (2003) Solitary fibrous tumor of the orbit: a clinicopathologic study of six cases with review of the literature. Surv Ophthalmol 48:544-554

74. Cerdá-Nicolás M, Löpez-Gines C, Gil-Benso R, Benito R, Pellin A, Ruiz-Saurí A, Sanchos-Garcia J, Roldan P, Talamantes F, Barberá J (2006) Solitary fibrous tumor of the orbit: morphological, cytogenetic and molecular features. Neuropathology 26:557-563

75. Ness GO, Lybaek H, Arnes J, Rødahl E (2005) Chromosomal imbalances in a recurrent solitary fibrous tumor of the orbit. Cancer Genet Cytogenet 162:38-44

76. Mukherjee B, Biswas J (2008) Solitary fibrous tumor of the orbit. Indian J Pathol Microbiol 51:453-455

77. Feuerman JM, Flint A, Elner VM (2010) Cystic solitary fibrous tumor of the orbit. Arch Ophthalmol 128:385-387. doi:10.1001/ archophthalmol.2009.405

78. Kitamura Y, Akiyama T, Hirose S, Yoshida K (2012) Optic nerve sheath solitary fibrous tumor. Acta Neurochir (Wien) 154:633-635. doi:10.1007/s00701-011-1257-1

79. Ali MJ, Honavar SG, Naik MN, Vemuganti GK (2013) Orbital solitary fibrous tumor: a rare clinicopathologic correlation and review of literature. J Res Med Sci 18:529-531

80. von Lovenberg E, Kedziora O, Wolf HK, Bankfalvi A (2013) Extraconal solitary fibrous tumor of the orbit. Ophthalmologe 110:357-359. doi:10.1007/s00347-012-2655-3

81. Meyer TN, Matos BH, Oliveira LR, Mendonça AT (2013) Report of a case of solitary fibrous tumour of the orbit. Oral Maxillofac Surg 17:225-227. doi:10.1007/s10006-012-0366-1

82. Pecorella I, Cruciani F, Russo V (2014) A solitary fibrous tumour of the eyelid. Med Princ Pract 23(2):170-173. doi:10.1159/000351577

83. Pe'er J, Maly A, Deckel Y et al (2007) Solitary fibrous tumor of the conjunctiva. Arch Ophthalmol 125(3):423-426

84. Kakizaki H, Maden A, Türe M, Ylmaz S, Chan WO (2010) Hemangiopericytoma - solitary fibrous tumor of the eyelid.
Ophthal Plast Reconstr Surg 26(1):46-48. doi:10.1097/IOP. 0b013e3181b8c4b3

85. Cho NH, Kie JH, Yang WI et al (1998) Solitary fibrous tumor with an unusual adenofibromatous feature in the lacrimal gland. Histopathology 33(3):289-290

86. Robinson DR, Wu YM, Kalyana-Sundaram S, Cao X et al (2013) Identification of recurrent NAB2-STAT6 gene fusions in solitary fibrous tumor by integrative sequencing. Nat Genet 45:180-185. doi:10.1038/ng.2509

87. Chmielecki J, Crago AM, Rosenberg M (2013) Whole-exome sequencing identifies a recurrent NAB2-STAT6 fusion in solitary fibrous tumors. Nat Genet 45:131-132. doi:10.1038/ng.2522

88. Doyle LA, Vivero M, Fletcher CD, Mertens F, Hornick JL (2014) Nuclear expression of STAT6 distinguishes solitary fibrous tumor from histologic mimics. Mod Pathol 27:390-395. doi:10.1038/ modpathol.2013

89. Mullings RE, Wilson SJ, Puddicombe SM (2001) Signal transducer and activator of transcription 6 (STAT-6) expression and function in asthmatic bronchial epithelium. J Allergy Clin Immunol 108:832-838

90. Schweizer L, Koelsche C, Sahm F, Piro RM (2013) Meningeal hemangiopericytoma and solitary fibrous tumors carry the NAB2STAT6 fusion and can be diagnosed by nuclear expression of STAT6 protein. Acta Neuropathol 125:651-658. doi:10.1007/ s00401-013-1117-6

91. Sugita S, Aoyama T1, Kondo K et al. (2104) Diagnostic utility of NCOA2 fluorescence in situ hybridization and Stat6 immunohistochemistry staining for soft tissue angiofibroma and morphologically similar fibrovascular tumors. Hum Pathol 45:1588-1596. doi: 10.1016/j.humpath.201

92. Yang BT, Wang YZ, Dong JY, Wang XY, Wang ZC (2012) MRI study of solitary fibrous tumor in the orbit. AJR Am J Roentgenol 199(4):W506-W511

93. Zhang Z, Guo J, Yan F, Fu L, Xian J (2013) Value of MR imaging in differentiation between solitary fibrous tumor and schwannoma in the orbit. AJNR Am J Neuroradiol 34:1067-1071. doi:10.3174/ajnr.A3340

94. Kim HJ, Kim HJ, Kim YD, Yim YJ, Kim ST, Jeon P, Kim KH, Byun HS, Song HJ (2008) Solitary fibrous tumor of the orbit: CT and MR imaging findings. AJNR Am J Neuroradiol 29:857-862. doi:10.3174/ajnr.A0961

95. Xian J, Zhang Z, Wang Z, Li J, Yang B, Chen Q, Chang Q, He L (2010) Evaluation of MR imaging findings differentiating cavernous haemangiomas from schwannomas in the orbit. Eur Radiol 20: 2221-2228. doi:10.1007/s00330-010-1774-y

96. Kato N, Kato S, Ueno H (1990) Hemangiopericytoma: characteristic features observed by magnetic resonance imaging and angiography. J Dermatol 17:701-706

97. Gengler C, Guillou L (2006) Solitary fibrous tumour and haemangiopericytoma: evolution of a concept. Histopathology 48: 63-74

98. Irion L, Bonshek R, Kumar A et al (2014) Orbital solitary fibrous tumor: case series and new perpectives. Acta Ophthalmol 92 (issue sup):s253

99. van Houdt WJ, Westerveld CM, Vrijenhoek JE, van Gorp J, van Coevorden F, Verhoef C, van Dalen T (2013) Prognosis of solitary fibrous tumors: a multicenter study. Ann Surg Oncol 20:4090-4095. doi:10.1245/s10434-013-3242-9

100. Streubel B, Simonitsch-Klupp I, Müllauer L et al (2004) Variable frequencies of MALT lymphoma-associated genetic aberrations in MALT lymphomas of different sites. Leukemia 18(10):1722-1726

101. Chanudet E, Ye H, Ferry J et al (2009) A20 deletion is associated with copy number gain at the TNFA/B/C locus and occurs preferentially in translocation-negative MALT lymphoma of the ocular adnexa and salivary glands. J Pathol 217(3):420-430. doi:10. 1002/path.2466 